Article

\title{
Anticoagulant Activity and Structural Characterization of Polysaccharide from Abalone (Haliotis discus hannai Ino) Gonad
}

\author{
Jun Zhao ${ }^{1}$, Jingfeng Yang ${ }^{2}$, Shuang Song ${ }^{2}$, Dayong Zhou ${ }^{2}$, Weizhou Qiao ${ }^{3}$, Ce Zhu ${ }^{2}$, \\ Shuyin Liu ${ }^{2}$ and Beiwei Zhu ${ }^{2, *}$ \\ 1 School of Light Industry and Chemical Engineering, Dalian Polytechnic University, Dalian 116034, China; \\ kittyufo@163.com \\ 2 School of Food Science and Technology, National Engineering Research Center of Seafood, \\ National and Local Joint Engineering Laboratory for Marine Bioactive Polysaccharide Development and \\ Application, Dalian Polytechnic University, Dalian 116034, China; yangjf@dlpu.edu.cn (J.Y.); \\ songs1008@163.com (S.S.); zdyzf1@163.com (D.Z.); silvia8801@163.com (C.Z.); 18340801443@163.com (S.L.) \\ 3 Clinical Laboratory, Dalian Municipal Central Hospital Affiliated of Dalian Medical University, \\ Dalian 116033, China; qiaoweizhouzxyy@163.com \\ * Correspondence: zhubeiwei@163.com; Tel./Fax: +86-411-8632-3262
}

Academic Editors: Isabel C. F. R. Ferreira and Nancy D. Turner

Received: 4 April 2016; Accepted: 23 May 2016; Published: 8 June 2016

\begin{abstract}
In this study, we aimed at characterizing the structure and the anticoagulant activity of a polysaccharide fraction (AGP33) isolated from the gonads of Haliotis discus hannai Ino. AGP33 was extracted by enzymatic hydrolysis and purified by ion-exchange and gel-filtration chromatography. The backbone fraction of AGP33 (BAGP33), which appeared to contain of mannose, glucose and galactose, was prepared by partial acid hydrolysis. According to methylation and nuclear magnetic resonance (NMR) spectroscopy, the backbone of AGP33 was identified as mainly consisting of $1 \rightarrow 3$-linked, $1 \rightarrow 4$-linked, and $1 \rightarrow 6$-linked monosaccharides. AGP33 is a sulfated polysaccharide with sulfates occur at 3-O- and 4-O-positions. It prolonged thromboplastin time (APTT), thrombin time (TT) and prothrombin time (PT) compared to a saline control solution in a dosage-dependent manner. AGP33 exhibited an extension $(p<0.01)$ of APTT compared to the saline group at concentrations higher than $5 \mu \mathrm{g} / \mathrm{mL}$. AGP33 exhibited higher anticoagulant activity than its desulfated product (AGP33-des) and BAGP33. The results showed that polysaccharide with higher molecular weight and sulfate content demonstrated greater anticoagulant activity.
\end{abstract}

Keywords: polysaccharide; Haliotis discus hannai; APTT; TT; PT; backbone

\section{Introduction}

Abalone, a very large edible sea snail, is a marine gastropod mollusc which belongs to the Haliotidae family. Haliotis discus hannai Ino has been regarded as a functional food since ancient times in China, and now the aquacultural production of this species reached 115,397 ton in 2014 [1] However, the gonads, which account for one-third of the total mass of abalone pleopod, are routinely discarded during processing. The disposal of the gonad not only leads to underutilization of valuable biomass, but also creates an environmental challenge of how to handle such a large quantity of biowastes.

An earlier study has shown that polysaccharides from abalone gonads were sulfated polymers accounting for one-tenth of the total gonad mass [2]. It is widely recognized that most of the sulfated polysaccharides can serve as anticoagulants [3-6]. For example, the potent anticoagulant heparin can activate antithrombin III, which blocks thrombin from clotting the blood stream. Heparin has been used in vivo and in vitro for clinical application in thrombotic desease [7]. However, the availability of 
heparin seems to be somewhat limited by its low concentration in porcine intestine or bovine lung, which are its main natural sources. Furthermore, the incidence of prion-related diseases in cows means that bovine heparin runs a risk of contamination which has to be carefully monitored. In the meantime, the ever-increasing demand for antithrombotic therapy calls for alternative sources of anticoagulant and antithrombotic compounds [8]. It has been shown that sulfated polysaccharides with anticoagulant activity are most abundant in marine invertebrates and marine algae $[9,10]$. Hence, abalone gonads could eventually become a valuable source of polysaccharides with anticoagulant properties.

In this study, we aimed at characterizing the structure and the anticoagulant activity of a polysaccharide fraction (AGP33) isolated from the gonads of abalone, whose potential can lead to a more effective commercial development of this natural product.

\section{Results and Discussion}

\subsection{Preparation and Characterization of Abalone Gonad Polysaccharides}

The crude abalone gonad polysaccharides were fractionated by a column of DEAE-52 cellulose, yielding three fractions. The fraction obtained in $0.5 \mathrm{M}$ sodium chloride was collected and further purified on a Sepharose CL-6B column to yield three sub-fractions as described by Yang et al. [2]. The third fraction (AGP33) eluted from Sepharose CL-6B has shown to be homogeneous by liquid chromatogrphy (peak (a), Figure 1). AGP33, with an average molecular weight of $27.5 \mathrm{~kg} / \mathrm{mol}$, contains $7.49 \% \pm 0.34 \%$ sulfate groups, and was composed of mannose, rhamnose, glucuronic acid, glucose, galactose, xylose, arabinose, and fucose. The optical rotation of AGP33 was found to be $[\alpha]_{589}^{25^{\circ} \mathrm{C}}=+103.3$ which allowed the confirmation of the homogeneity of this fraction.

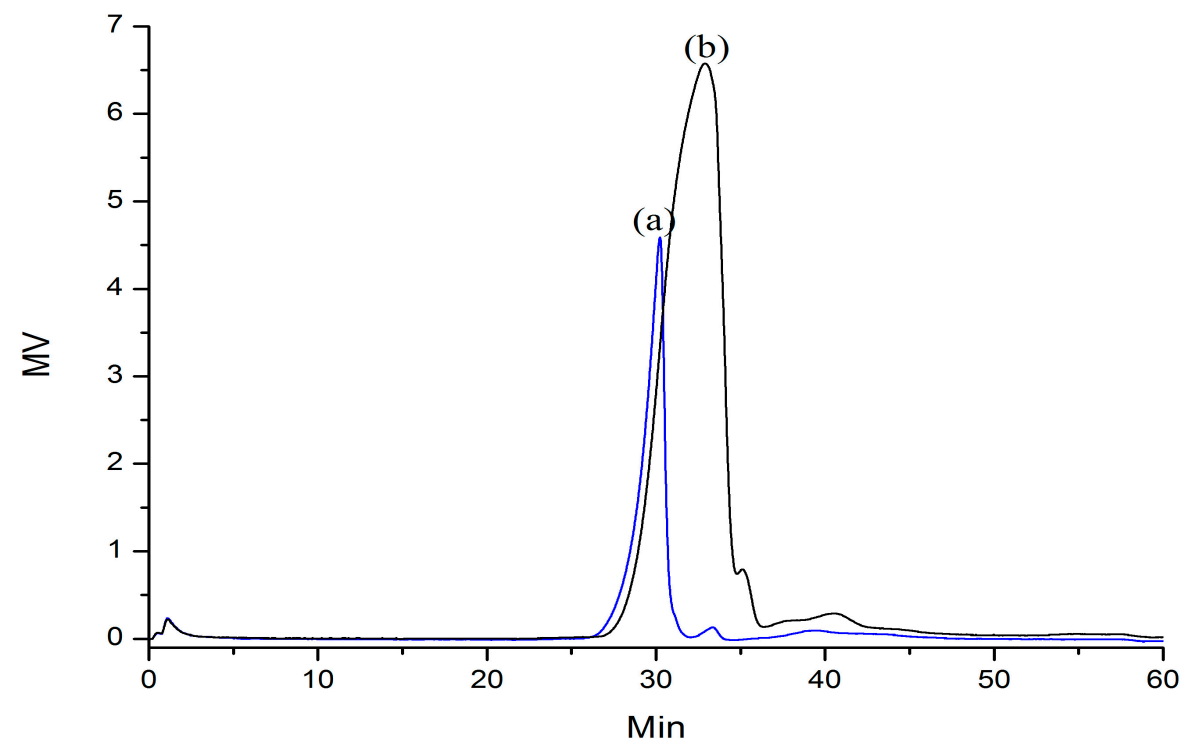

Figure 1. Elution profile of AGP33 (a) and its hydrolysis product BAGP33 (b) on SEC chromatography using a differential refraction detector.

\subsection{Partial Acid Hydrolysis of AGP33}

BAGP33, the partial acid hydrolysis product of AGP33, appeared as a single symmetrical peak in its size exclusion chromatogram, suggesting that it was in its pure form. As shown in Figure 1, peak (b), the retention time of BAGP33 was a bit longer than that of AGP33, suggesting a possible degradation reaction caused a decrease of the molecular weight, indicating that the backbone of AGP33 was maintained in BAGP33, while the branches were cleaved after hydrolysis. BAGP33, with an average molecular weight of $17.0 \mathrm{~kg} / \mathrm{mol}$, contains $1.71 \% \pm 0.03 \%$ sulfate groups. The monosaccharide 
composition of BAGP 33 appeared to be mannose, glucose and galactose, which were also the building blocks of AGP33.

\subsection{Methylation Analysis of BAGP33}

BAGP33 was then fully methylated and hydrolyzed with trifluoroacetic acid (TFA). It was converted into alditol acetates, and analyzed by GC-MS. As summarized in Table 1, the types of linkage of the monomers were identified. BAGP33 exhibited five types of monosaccharide linkages, including $1 \rightarrow 3$-linked $\alpha$-D-glucose, $1 \rightarrow 4$-linked $\alpha$-D-galactose, and $1 \rightarrow 6$-linked $\alpha$-D-glucose, mannose and galactose. The lack of branched linkages in BAGP33 indicated that BAGP33 was the backbone of AGP33, since most the side chains of AGP33 were removed during acidic hydrolysis.

Table 1. Methylation analysis of BAGP33 and the NMR spectrum signals assigned for AGP33.

\begin{tabular}{|c|c|c|c|c|c|c|c|c|c|}
\hline \multirow{3}{*}{\multicolumn{2}{|c|}{ Linkage Pattern }} & \multicolumn{2}{|c|}{ Methylation Analysis } & \multicolumn{6}{|c|}{$\begin{array}{l}\text { Chemical Shifts }(\delta) \text { for the } \\
\text { Carbon and Hydrogen Atoms }\end{array}$} \\
\hline & & \multirow{2}{*}{ Methylated Product } & \multirow{2}{*}{$\begin{array}{l}\text { Molar } \\
\text { Ratio }\end{array}$} & $\mathrm{C} 1$ & $\mathrm{C} 2$ & $\mathrm{C} 3$ & $\mathrm{C} 4$ & C5 & C6 \\
\hline & & & & H1 & $\mathrm{H} 2$ & H3 & $\mathrm{H} 4$ & H5 & H6 \\
\hline A & $\rightarrow 3)-\alpha$-D-Glc $p(1 \rightarrow$ & $1,3,5-\mathrm{Ac}_{3}-2,4,6-\mathrm{Me}_{3}-\mathrm{Glc}$ & 6.7 & $\begin{array}{l}101.02 \\
5.29\end{array}$ & $\begin{array}{l}76.54 \\
3.92\end{array}$ & $\begin{array}{l}77.69 \\
4.45\end{array}$ & $\begin{array}{l}72.48 \\
3.75\end{array}$ & $\begin{array}{l}72.23 \\
4.35\end{array}$ & $\begin{array}{c}60.53 \\
3.58,4.18\end{array}$ \\
\hline B & $\rightarrow 4)-\alpha-\mathrm{D}-\mathrm{Gal} p(1 \rightarrow$ & $1,4,5-\mathrm{Ac}_{3}-2,3,6-\mathrm{Me}_{3}-\mathrm{Gal}$ & 13.3 & $\begin{array}{l}99.64 \\
5.52\end{array}$ & $\begin{array}{l}76.54 \\
3.92\end{array}$ & $\begin{array}{l}77.23 \\
4.35\end{array}$ & $\begin{array}{l}81.36 \\
3.75\end{array}$ & $\begin{array}{l}72.23 \\
4.35\end{array}$ & $\begin{array}{c}60.53 \\
3.58,4.18\end{array}$ \\
\hline $\mathrm{C}$ & $\rightarrow 6)-\alpha$-D-Glcp $(1 \rightarrow$ & 1,5,6-Ac $-2,3,4-\mathrm{Me}_{3}-\mathrm{Glc}$ & 6.3 & $\begin{array}{l}100.51 \\
5.09\end{array}$ & $\begin{array}{l}76.21 \\
3.92\end{array}$ & $\begin{array}{l}77.23 \\
4.35\end{array}$ & $\begin{array}{l}72.68 \\
3.75\end{array}$ & $\begin{array}{l}72.23 \\
4.35\end{array}$ & $\begin{array}{c}69.54 \\
3.98,4.45\end{array}$ \\
\hline & $\rightarrow 6)-\alpha$-D-Man $p(1 \rightarrow$ & 1,5,6- $\mathrm{Ac}_{3}-2,3,4-\mathrm{Me}_{3}-\mathrm{Man}$ & 6.0 & $\begin{array}{l}101.70 \\
5.09\end{array}$ & $\begin{array}{l}76.21 \\
3.92\end{array}$ & $\begin{array}{l}77.23 \\
4.35\end{array}$ & $\begin{array}{l}72.68 \\
3.75\end{array}$ & $\begin{array}{l}72.23 \\
4.35\end{array}$ & $\begin{array}{c}70.3 \\
3.93,4.18\end{array}$ \\
\hline & $\rightarrow 6)-\alpha-\mathrm{D}-\mathrm{Gal} p(1 \rightarrow$ & $1,5,6-\mathrm{Ac}_{3}-2,3,4-\mathrm{Me}_{3}-\mathrm{Gal}$ & 3.2 & $\begin{array}{l}101.02 \\
5.07\end{array}$ & $\begin{array}{l}76.21 \\
3.92\end{array}$ & $\begin{array}{l}77.01 \\
4.35\end{array}$ & $\begin{array}{l}72.59 \\
3.75\end{array}$ & $\begin{array}{l}72.23 \\
4.35\end{array}$ & $\begin{array}{c}68.3 \\
4.08,4.18\end{array}$ \\
\hline
\end{tabular}

\section{4. ${ }^{13} \mathrm{C}$ - and ${ }^{1} \mathrm{H}-\mathrm{NMR}$ Analysis of AGP33}

The ${ }^{13} \mathrm{C}-\mathrm{NMR}$ and ${ }^{1} \mathrm{H}-\mathrm{NMR}$ spectra of AGP33 are shown in Figure 2. The ${ }^{1} \mathrm{H}-\mathrm{NMR}$ spectrum shows strong anomeric H-1 ( $\delta 5.52,5.29,5.09$ and $5.07 \mathrm{ppm})$ proton signals, indicating the $\alpha$-configuration of AGP33 monomers [11]. As shown in the ${ }^{13}$ C-NMR spectrum of AGP33, the resonances in the region of $\delta 97-101 \mathrm{ppm}$ for C-1 can be attributed to the anomeric carbon atoms of pyranose, as the furan ring signals can be observed around $\delta 107-109 \mathrm{ppm}$ [12]. Peaks presented at $\delta 101.02,100.51$, and 99.64 ppm correspond to C-1 of the $1 \rightarrow 3-\alpha-D-G l c p, 1 \rightarrow 6-\alpha-D-G l c p$, and $1 \rightarrow 4-\alpha-\mathrm{D}-\mathrm{Gal} p$ residues, respectively. All the carbon signals indicate that they are all $\alpha$-anomeric configuration [13]. The carbon signal correlated with the resonances at $\delta 69.54 \mathrm{ppm}$ can be assigned to C-6 of the $1 \rightarrow 6-\alpha-\mathrm{D}-\mathrm{Glc} p$, which is shifted about 9 ppm downfield compared to the resonance of standard methyl glycoside due to the effect of glycosylation [14]. Similarly, the signals at $\delta 77.69$ and 81.36 ppm are assigned to C-3 of $1 \rightarrow 3-\mathrm{D}-\mathrm{Glc} p$ and C-4 of $1 \rightarrow 4-\mathrm{D}-\mathrm{Gal} p$, respectively. Due to the fact that BAGP33 is the backbone of AGP33, the NMR spectra signal of BAGP33 is essentially in accord with the signal of AGP33. The AGP33 signals in the ${ }^{13} \mathrm{C}-\mathrm{NMR}$ spectrum are summarized in Table 1 , which are in good agreement with the BAGP33 methylation results. Other signals in the ${ }^{13} \mathrm{C}-\mathrm{NMR}$ and ${ }^{1} \mathrm{H}-\mathrm{NMR}$ spectra (Table 1) are assigned based on their correlation with correlated spectroscopy $\left({ }^{1} \mathrm{H}-{ }^{1} \mathrm{H}\right.$ COSY) and heteronuclear single-quantum coherence (HSQC) experiments [6,12]. 
(a)
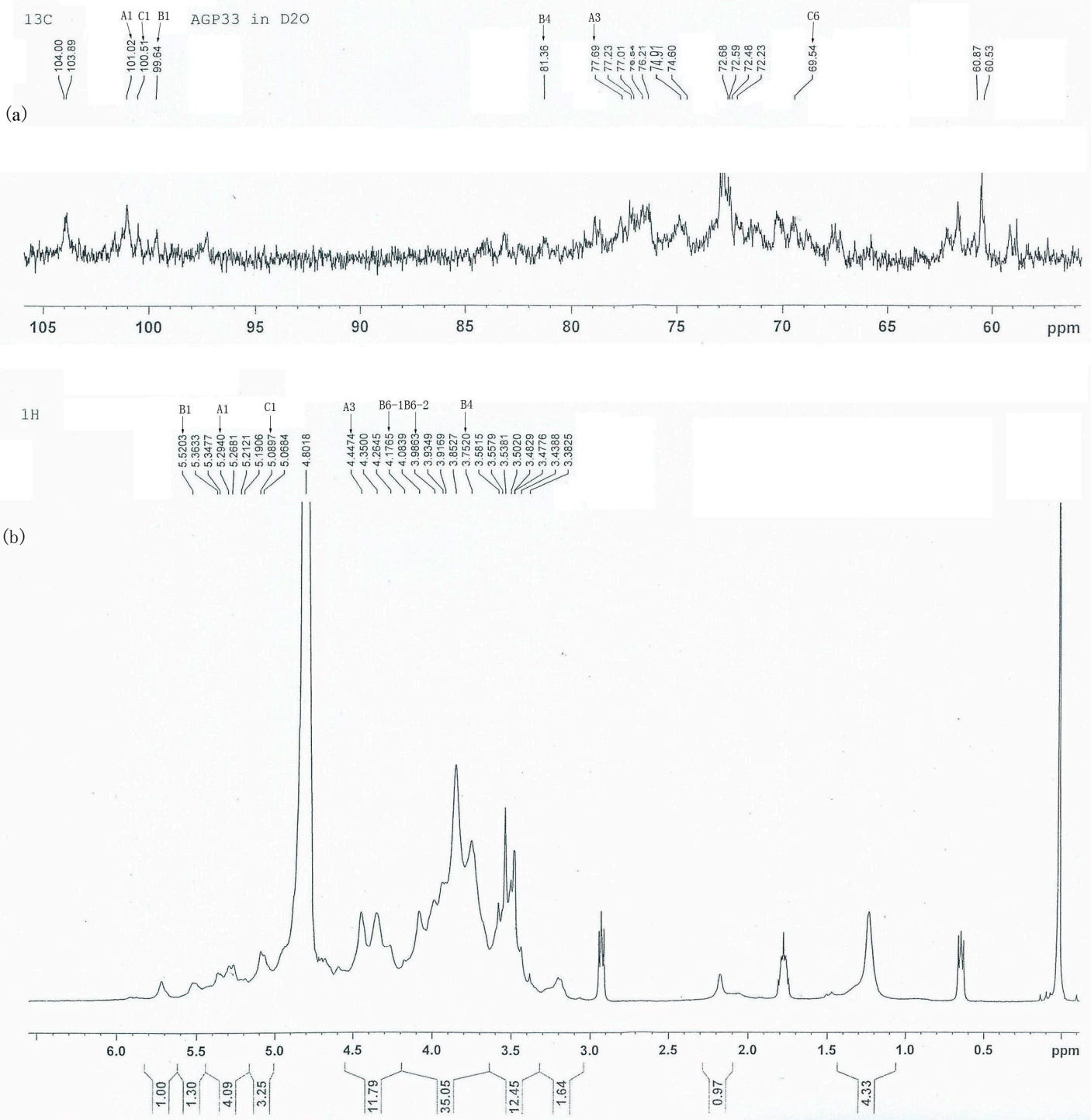

Figure 2. ${ }^{13} \mathrm{C}-\mathrm{NMR}(\mathbf{a})$ and ${ }^{1} \mathrm{H}-\mathrm{NMR}(\mathbf{b})$ spectrum of AGP33. Residues A: 1,3-D-Glcp, Residues B: 1,4-D-Gal $p$ and Residues C: 1,6-D-Glcp.

\subsection{HSQC Analysis of AGP33}

The one-bond correlations of the ${ }^{13} \mathrm{C}$ - and ${ }^{1} \mathrm{H}-\mathrm{NMR}$ spectra (Figure $3 \mathrm{a}$ ) showed three main cross peaks in their anomeric regions. The $\mathrm{C}-1$ signals at $\delta_{\mathrm{C}-1} 101.02$ and $\delta_{\mathrm{C}-1} 99.64$, assigned to the 1,3-D-Glcp (residue A) and 1,4-D-Galp (residues B), showed cross-peaks with the $\mathrm{H}-1$ resonance peaks at $\delta_{\mathrm{H}-1} 5.29$ and $\delta_{\mathrm{H}-1}$ 5.52. The $\mathrm{H}-1$ peak at $\delta_{\mathrm{H}-1} 5.09$ was assigned to $1,6-\mathrm{D}-\mathrm{Glc} p$ (residues $\mathrm{C}$ ), since it correlated to the $\mathrm{C}-1$ peak at $\delta_{\mathrm{C}-1} 100.51$. The cross peak between $\mathrm{C}-4$ at $\delta_{\mathrm{C}-4} 81.36$ and the proton resonance at $\delta_{\mathrm{H}-4} 3.75$ allowed it to be assigned to the H-4-C-4 resonance of 1,4-D-Galp. The cross peak between C-3 at $\delta_{\mathrm{C}-3} 77.69$ and the proton resonance at $\delta_{\mathrm{H}-3} 4.45$ allowed it to be assigned to the $\mathrm{H}-3-\mathrm{C}-3$ resonance of 1,3-D-Glcp. The H-6 resonance peaks appeared as doublets due to their coupling to each other. The C-6 peaks of 1,6-D-Glcp at $\delta 69.54$ correlated well with the resonance peaks at $\delta_{\mathrm{H}-4} 3.98$ and 4.45 . Some correlations between protons and their directly bonded carbons in 1,6-D-Gal $p$ and 1,6-D-Man $p$ were also observed in the HSQC spectrum, and these signals were useful for the assignment of their ${ }^{1} \mathrm{H}$ and ${ }^{13} \mathrm{C}$ resonances (Table 1 ). 


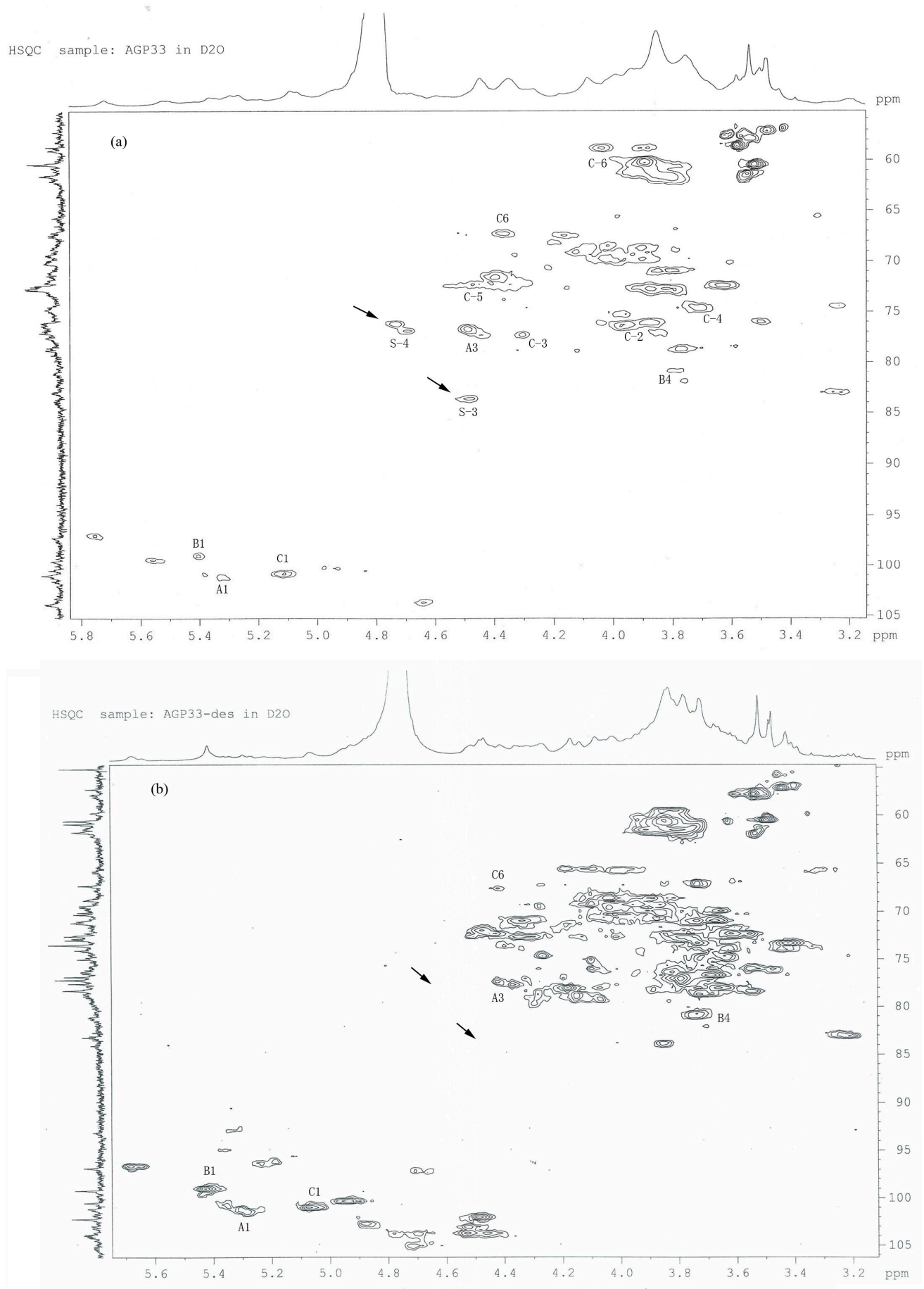

Figure 3. (a) HSQC spectrum of AGP33; (b) HSQC spectrum of AGP33-des (AGP33 without the sulfate group). The cross-peaks were assigned to 1,3-D-Glcp (residues A), 1,4-D-Galp (residues B) and 1,6-D-Glcp (residues C). S-4: sulfate group in 4-O-position; S-3: sulfate group in 3-O-position.

\section{6. ${ }^{1} \mathrm{H}^{-1} \mathrm{H}$ COSY Analysis of AGP33}

From the COSY spectrum shown in Figure 4 , it was possible to correlate the $\mathrm{H}-1$ of residue $\mathrm{A}\left(\delta_{\mathrm{H}-1}\right.$ 5.29) with $\mathrm{H}-2\left(\delta_{\mathrm{H}-2} 3.92\right)$. The $\mathrm{H}-1$ of residue $\mathrm{B}\left(\delta_{\mathrm{H}-1} 5.52\right)$ correlates well with $\mathrm{H}-2\left(\delta_{\mathrm{H}-2} 3.92\right)$. The $\mathrm{H}-1$ of the 1, 6-D-Glc $p$, residues $\mathrm{C}\left(\delta_{\mathrm{H}-1} 5.09\right)$ correlates well with $\mathrm{H}-2\left(\delta_{\mathrm{H}-2} 3.92\right)$. The corresponding $\mathrm{C}-2$ and $\mathrm{C}-3$ were also assigned in the HSQC spectrum. The peaks of $\mathrm{H}-2, \mathrm{H}-3, \mathrm{C}-2$ and C-3 of the remaining residues (Table 1) were assigned by similar procedures. 


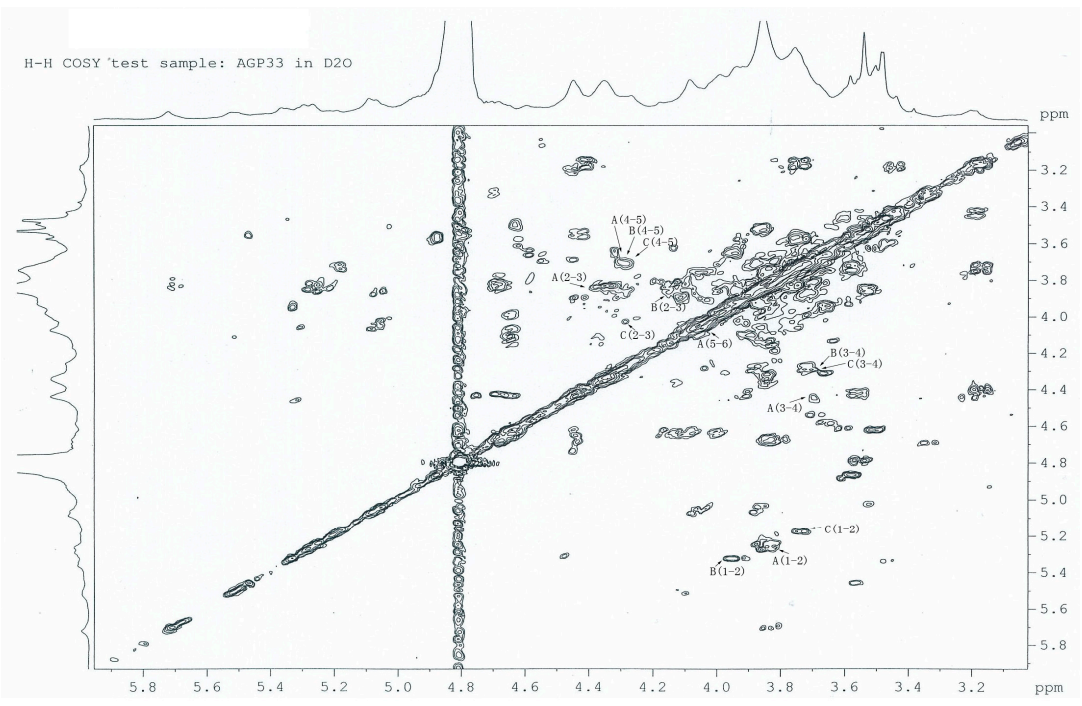

Figure 4. H, H-COSY spectrum of AGP33. The cross-peaks were showed the correlate of two adjacent hydrogen atom of each residue in which 1,3-D-Glcp, 1,4-D-Galp and 1,6-D-Glcp referred to residues A, B and $C$ respectively.

\subsection{Heteronuclear Multiple-Bond Correlation $\left({ }^{1} \mathrm{H}_{-}{ }^{13} \mathrm{C}-\mathrm{HMBC}\right)$ Analysis of AGP33}

The $\mathrm{C}$ resonance peaks of 1,3-D-Glcp (residue A), 1,4-D-Gal $p$ (residue B) and 1,6-D-Glcp (residue C) were assigned by the analysis of the HMBC spectrum (Figure 5). In the HMBC spectrum, cross peaks H-1-C-6 (linkages of residue $C, \delta_{C-6} 69.54$ to residues $B, \delta_{\mathrm{H}-1}$ 5.52) are identified. This result suggests that the $\mathrm{H}-1$ of $1,4-\mathrm{D}-\mathrm{Gal} p$ is linked directly to $\mathrm{C}-6$ of the $1,6-\mathrm{D}-\mathrm{Glc} p$ residue. The cross peak at $\delta_{\mathrm{H}-1} 5.52$ and the resonances at $\delta_{\mathrm{C}-6} 69.54$ in HMBC spectrum indicate that 1,4-D-Galp residues and 1,6-D-Glc $p$ residues are also linked directly, constituting a disaccharide of the backbone of AGP33.

Based on the experimental data above, we deduced that the backbone of AGP33 may be consisted of $(1 \rightarrow 4)$-linked galactose and $(1 \rightarrow 6)$-linked glucose, linked together as a disaccharide unit of $[\rightarrow 4)-\alpha$-Gal $p-(1 \rightarrow 6)-\alpha-$ Glc $p-(1 \rightarrow]_{n}$.

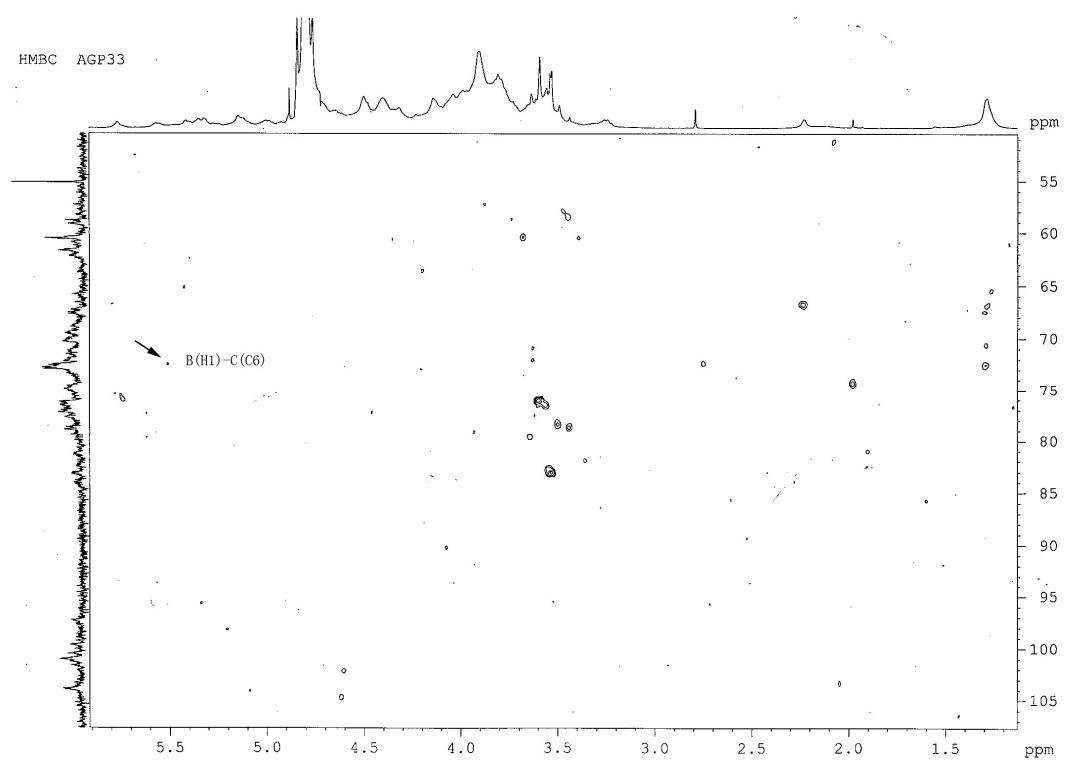

Figure $5 .{ }^{1} \mathrm{H}-{ }^{13} \mathrm{C}-\mathrm{HMBC}$ spectrum of AGP33. The cross-peaks demonstrate that $1,4-\mathrm{D}-\mathrm{Gal} p$ (residue B) links directly to $1,6-\mathrm{D}-\mathrm{Glc} p$ (residue C). 


\subsection{Analysis of the Position of the Sulfate Groups in AGP33}

After the sample of AGP33 was desulfated (AGP33-des), the sulfate group position in AGP33 was detected by HSQC spectroscopy. The HSQC spectrum of AGP33-des was similar to that of AGP33 except for the two cross-peaks related to the sulfate groups, which disappeared in AGP33-des (Figure $3 \mathrm{~b}$ ). The cross peak at resonances $\delta_{\mathrm{H}-1} 4.45$ and $\delta_{\mathrm{C}-6} 84.01$ in HSQC spectrum was identified as a signal of a sulfate group acting on its adjacent 3-O-position atom in the monosaccharide (Figure 3a). Similarly, the cross peak at resonances $\delta_{\mathrm{H}-1} 4.72$ and $\delta_{\mathrm{C}-6} 77.69$ was identified as a signal of a sulfate group acting on its adjacent 4-O-position atom in monosaccharide (Figure 3a). The disappearance of the two cross-peaks in AGP33-des was attributed to the removal of the sulfate groups from their original position. Based on the above results, we suggest that sulfation of AGP33 might occur at 3-Oand 4-O-positions.

\subsection{Anticoagulant Activity}

The anticoagulant activity of AGP33 was evaluated by the classical coagulation assays for activated partial thromboplastin time (APTT), thrombin time (TT) and prothrombin time (PT), with normal saline solution (NS, $0.9 \%, w / v)$ as the negative control and heparin sodium (HS, $0.5 \mu \mathrm{g} / \mathrm{mL}$ ) as the positive control. As shown in Figure 6, AGP33 extended APTT, PT and TT in a dosage-dependent manner. AGP33 exhibited a significant extension $(p<0.01)$ in TT, compared to the negative control, when its concentration was higher than $25 \mu \mathrm{g} / \mathrm{mL}$. Transformation of fibrinogen into fibrin is known to be the last step in coagulation, and TT is a key indicator of this process. Hence, AGP33 might inhibit the conversion of fibrinogen into fibrin [6]. APTT was also extended significantly $(p<0.01)$ when AGP33 concentration was higher than $25 \mu \mathrm{g} / \mathrm{mL}$ when compared to the negative control. APTT is used to evaluate the coagulation factors such as VIII, IX, X, XII and prekallikrein in the intrinsic blood coagulation pathway [15]. These results confirmed that AGP33 may interfere with the coagulation factors (VIII, IX, X, XII) during the intrinsic coagulation process. PT was extended significantly $(p<0.01)$ when AGP33 concentration was higher than $100 \mu \mathrm{g} / \mathrm{mL}$. As PT is used to characterize the extrinsic coagulation factors, these results obtained for the anticoagulant activity suggest that AGP33 may inhibit both the intrinsic and the common coagulation pathways.

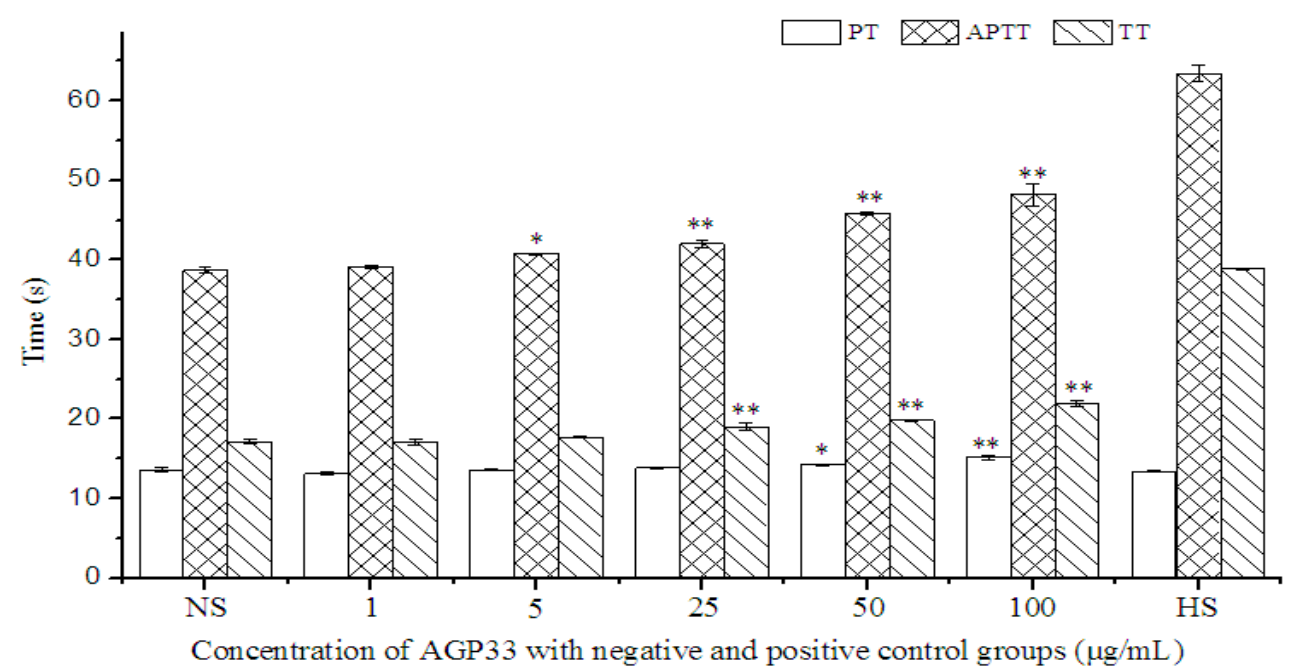

Figure 6. AGP33 prolonged APTT, PT and TT compared to normal saline (NS) group as a dose-dependent manner. The "** means different to NS group $(p<0.05)$ and “*** means significant different to NS group $(p<0.01)$. HS was set as the positive control with concentration of $0.5 \mu \mathrm{g} / \mathrm{mL}$.

The anticoagulant activity of AGP33-des and BAGP33 were tested. All the samples prolonged APTT in the concentration of $50 \mu \mathrm{g} / \mathrm{mL}$, as shown in Figure 7. BAGP33 and AGP33-des showed 
differences from the blank control NS group in APTT but they could not prolong PT and TT. It was stated that the anticoagulant activity is associated to the high sulfate content of polysaccharides [16]. The low anticoagulant activity of AGP33-des supported this opinion. BAGP33 is the major fraction of AGP33 with little anticoagulant activity. This result suggested that both the molecular weight and degree of sulfation have essential influences on the anticoagulant activity of polysaccharides. Furthermore, the anticoagulant properties of the polysaccharides do not depend only on the percentage of sulphate residues, but rather, mostly on the distribution or position of sulphate groups and probably on the configuration of the polymer chains [9].

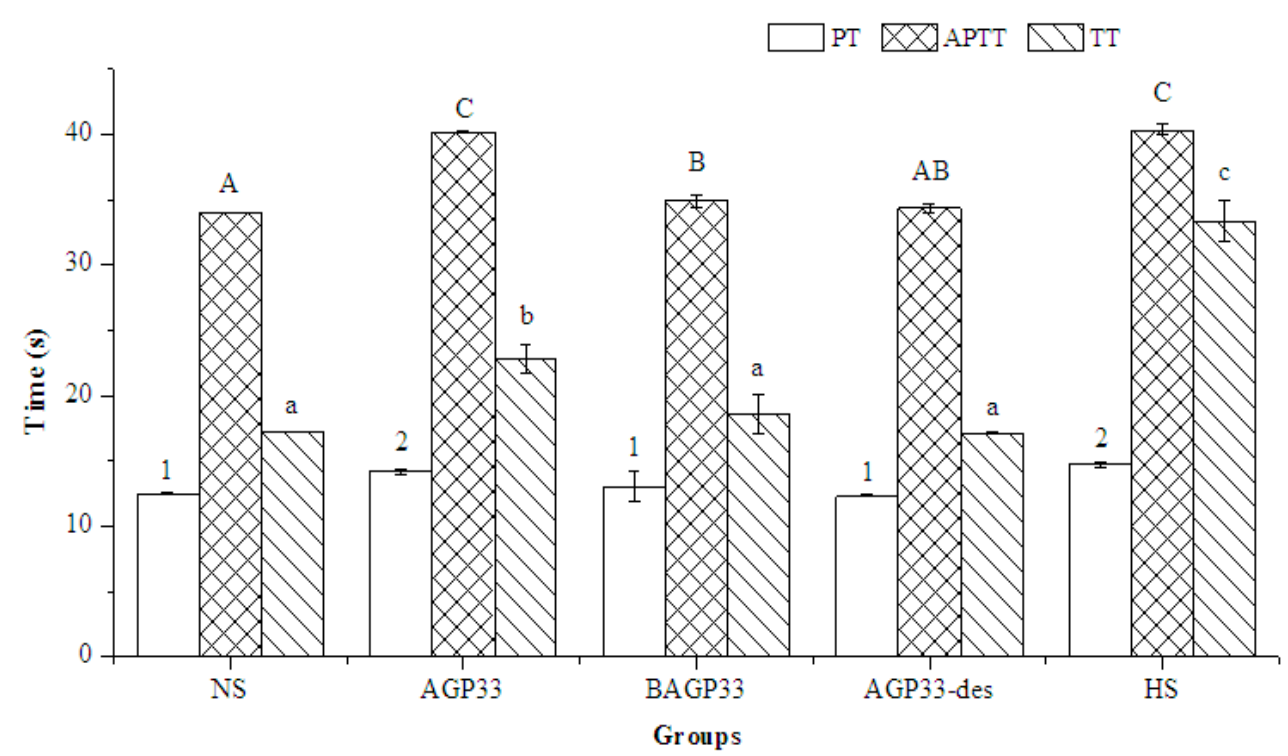

Figure 7. The anticoagulant activity of AGP33 compared with AGP33-des and BAGP33 at concentration of $50 \mu \mathrm{g} / \mathrm{mL}$. NS means normal saline group. HS was a positive control with concentration of $0.5 \mu \mathrm{g} / \mathrm{mL}$. Results are presented as means \pm standard deviations $(n=3)$. Significant differences between different groups were evaluated by One-Way ANOVA (post hoc test: S-N-K). Values in the same dose of different groups with different numbers (1-2), lower case letters (a-c) and capital letters (A-C) are significantly different at $p<0.05$.

Previous studies indicated that there are many factors that affect the biological activity of polysaccharides, not only the structure, the configuration of the polymer molecules, the concentration of sulfate [9,10], molecular weight and branching structures [17], but also the position of sulfate groups, since the interaction of sulfated polysaccharides with coagulation cofactors and their target protease are specific [18]. There is an argument about how the sulfation pattern influences the anticoagulant activity of sulfated polysaccharides. The anticoagulant activity of sulfated cellulose significantly increased with the content of sulfate in the C-2 and C-3 sites, but not in the C-6 site [18]. On the other hand, a study on the anticoagulant properties of citrus pectin showed that the polysaccharide became more potent with the sulfation at C-6 [3]. AGP33 is a polysaccharide with sulfate substitutents at the 3-Oand 4-O-position. Although AGP33 can extend APTT and exhibited an extension $(p<0.05)$ compared to the negative control with concentration of $5 \mu \mathrm{g} / \mathrm{mL}$, the polysaccharide of $\mathrm{CP}-\mathrm{CR}_{4} \mathrm{~S}$ sulfated at the 6-O-position showed a doubling of APTT at a concentration of $4.9 \mu \mathrm{g} / \mathrm{mL}$ [3]. AGP33 with sulfate at the 3-O- and 4-O-position has less potency compared to $\mathrm{CP}-\mathrm{CR}_{4} \mathrm{~S}$ sulfated at the 6-O-position at the same concentration. The absence of sulfate at the 6-O-position in AGP33 may explain its low anticoagulant activity. Therefore, the distribution of sulfate at the 6-O-position may be one of the crucial factors for the anticoagulant activity of the polysaccharides. 


\section{Experimental Section}

\subsection{Materials and Reagents}

Gonads of abalone ( $H$. discus hannai Ino) were obtained from Dalian Zhangzidao Group Co., Dalian, China. The fresh gonads were freeze-dried and smashed before extraction. Trifluoroacetic acid, monosaccharide standards, dextran molecular weight standards and MD-25 dialysis tubes (MWCO $7 \mathrm{~kg} / \mathrm{mol}$ ) were purchased from Sigma-Aldrich (St. Louis, MO, USA). Cellulose DEAE-52 and Sepharose CL-6B were purchased from Amersham Co. (Uppsala, Sweden). Activated partial thromboplastin time reagent (APTT, ellagic and bovine phospholipid), $\mathrm{CaCl}_{2}$ solution, prothrombin time (PT) reagent and thrombin time (TT) reagents were purchased from Stago Co. (Paris, France). All chemicals used in this study were of analytical reagent grade or above.

\subsection{General Methods}

The NMR spectra were recorded in $\mathrm{D}_{2} \mathrm{O}$ on an AV-500 spectrometer (Bruker, Bremen, Germany) operating at 500.13 and $125.75 \mathrm{MHz}$, respectively. The polysaccharide was dissolved in $\mathrm{D}_{2} \mathrm{O}$, and chemical shifts were referenced with $\mathrm{Me}_{4} \mathrm{Si}$. Sulfate content was assessed by barium chloride method using potassium sulfate as the standard [19]. Desulfation of polysaccharide was carried out using the pyridinium salts [20]. The sulfate group positions in the polysaccharide were revealed by HSQC spectroscopy (Bruker). All chromatographic assays were conducted with the phenol-sulfuric acid detection method [21].

\subsection{Isolation, Purification and Molecular Weight Determination of Abalone Gonad Polysaccharide}

The isolation and purification of the polysaccharide fraction AGP33 was conducted as previously reported [2]. The homogeneity of AGP33 was determined using a Waters e2695 liquid chromatography system (Waters, Milford, MA, USA) equipped with a TSK-gel G4000PWXL (TOSOH, Tokyo, Japan) column $(7.8 \mathrm{~mm} \times 300 \mathrm{~mm})$ and a differential refraction detector of 2414 (Waters). Ten $\mu \mathrm{L}$ of sample solution $(1 \mathrm{mg} / \mathrm{mL})$ was analyzed in each run, with distilled water as the eluent at a flow rate of $0.2 \mathrm{~mL} / \mathrm{min}$. The molecular weights of samples were determined by a column of Sepharose CL-6B $(1.6 \mathrm{~cm} \times 80 \mathrm{~cm})$, eluted with $0.15 \mathrm{M} \mathrm{NaCl}$ at a flow rate of $15 \mathrm{~mL} / \mathrm{h}$. The column was calibrated by dextran standards $\left(6.7 \times 10^{5} \mathrm{~g} / \mathrm{mol}, 4.1 \times 10^{5} \mathrm{~g} / \mathrm{mol}, 2.7 \times 10^{5} \mathrm{~g} / \mathrm{mol}, 8 \times 10^{4} \mathrm{~g} / \mathrm{mol}, 1.2 \times 10^{4} \mathrm{~g} / \mathrm{mol}\right.$, Sigma-Aldrich $)$.

\subsection{Monosaccharide Composition of AGP33}

The monosaccharide composition of AGP33 was assessed by submitting their acetylated aldononitrile derivatives to gas chromatography, according to Rajendra et al. with some modifications [22]. Briefly, AGP33 (10 mg) was hydrolyzed with $2.0 \mathrm{M}$ TFA $(2 \mathrm{~mL})$ at $100{ }^{\circ} \mathrm{C}$ for $4 \mathrm{~h}$, followed by evaporation with nitrogen gas to dryness. The residue was then mixed with hydroxylamine hydrochloride $(8 \mathrm{mg})$, inositol $(1 \mathrm{mg})$ and pyridine $(1 \mathrm{~mL})$, and incubated at $90{ }^{\circ} \mathrm{C}$ for $30 \mathrm{~min}$. After allowing it to cool down to room temperature, the mixture was acetylated with acetic anhydride $(0.5 \mathrm{~mL})$ at $90{ }^{\circ} \mathrm{C}$ for $30 \mathrm{~min}$. The alditol acetate was examined by gas chromatography (GC) on an Agilent $6890 \mathrm{~N}$ system (Agilent, Palo Alto, CA, USA) equipped with a HP-5 column $(0.32 \mathrm{~mm} \times 30 \mathrm{~m})$ and a flame-ionization detector. Nitrogen was used as the carrier gas $(1 \mathrm{~mL} / \mathrm{min})$. The injector temperature was kept at $250{ }^{\circ} \mathrm{C}$ (split injection 20:1). The operation was performed at a column temperature programmed for $130{ }^{\circ} \mathrm{C}$, holding for $5 \mathrm{~min}$, then increasing to $200^{\circ} \mathrm{C}$ at $3^{\circ} \mathrm{C} / \mathrm{min}$, holding for $5 \mathrm{~min}$ and increasing to $240{ }^{\circ} \mathrm{C}$ at $3^{\circ} \mathrm{C} / \mathrm{min}$, finally holding for $1 \mathrm{~min}$ at $240^{\circ} \mathrm{C}$.

\subsection{Partial Acid Hydrolysis and Purification of Depolymerized AGP33}

AGP33 (50 mg) was dissolved in 0.05 M TFA solution $(2 \mathrm{~mL})$ in a hydrolysis tube. After that, the tube was filled with pure nitrogen gas to replace the original air. The mixture was incubated at $95{ }^{\circ} \mathrm{C}$ for $3 \mathrm{~h}$, centrifuged at $10,000 \mathrm{~g}$ for $3 \mathrm{~min}$ and then the supernatant was recovered. TFA in the supernatant 
was removed by evaporation and then the sample was purified by passing through a column of Sephadex G-75. The main polysaccharide fraction, named BAGP33, was recovered, dialyzed, and lyophilized for further analysis.

\subsection{Methylation Analysis of BAGP33}

BAGP33 was methylated according to the method of Needs and Selvendran [23]. The completion of methylation was evidenced by the disappearance of the hydroxyl absorption peak at $3400 \mathrm{~cm}^{-1}$ in the IR spectrum. The methylated product was depolymerized with $85 \%$ formic acid for $4 \mathrm{~h}\left(100{ }^{\circ} \mathrm{C}\right)$ and then further hydrolyzed with $2 \mathrm{M}$ TFA for $6 \mathrm{~h}$ at the same temperature. The hydrolysates were then reduced and acetylated. The products were quantitatively analyzed by GC-MS method [24]. The exact types of methylated alditol acetates and their molar ratios were obtained.

\subsection{Blood Coagulation Assays}

APTT, TT and PT tests were used for the determination of the anticoagulant activity of the polysaccharide in vitro. Human blood samples were obtained from healthy donors in Dalian Central Hospital, Liaoning Province, China. Each sample was mixed with sodium citrate solution $(3.8 \%, w / w)$ at a ratio of 9:1 $(v / v)$. The mixture was centrifuged at $3000 \mathrm{~g}$ for $10 \mathrm{~min}$ to isolate the human plasma for further usage. The polysaccharide AGP33 was dissolved in saline solution $(0.9 \%, w / w)$ to a final concentration of $1,5,25,50$ and $100 \mu \mathrm{g} / \mathrm{mL}$, respectively, and mixed with human plasma to form solutions for the following anticoagulant evaluation. For APTT clotting assay, the mixture of plasma and AGP33 $(0.1 \mathrm{~mL})$ prepared as described above was mixed with $0.1 \mathrm{~mL}$ APTT reagent and incubated at $37{ }^{\circ} \mathrm{C}$ for $3 \mathrm{~min}$. Pre-incubated $0.1 \mathrm{~mL}$ of $0.025 \mathrm{M} \mathrm{CaCl}_{2}$ solution was added and clotting time was recorded with an automated coagulometer (Stago-R, Pairs, France). In PT clotting measurement, the mixture of plasma and AGP33 $(0.1 \mathrm{~mL})$ prepared as described above was incubated at $37^{\circ} \mathrm{C}$ for $2 \mathrm{~min}$; then $0.2 \mathrm{~mL}$ of pre-incubated PT reagent was added, and the clotting time was recorded. For TT clotting test, the mixture of plasma and AGP33 $(0.1 \mathrm{~mL})$ prepared as described above was incubated at $37^{\circ} \mathrm{C}$ for $2 \mathrm{~min}$ and $0.2 \mathrm{~mL}$ of pre-incubated TT reagent was added, and the clotting time was recorded. All assays were repeated three times and mean values calculated.

\subsection{Statistical Analysis}

All the tests were conducted with three replicates $(n=3)$. Data are presented as mean \pm standard deviation (SD). Mean values were compared by One-factor Analysis of Variance (ANOVA) and the differences between means were evaluated by using S-N-K test as well as $t$-test. The statistical analysis was performed by using SPSS 16.0 software (SPSS Inc. Chicago, IL, USA). Comparisons that yielded $p$ values $<0.05$ were considered significant.

\section{Conclusions}

The sulfated polysaccharide fraction isolated from the gonads of abalone (AGP33) is composed of mannose, rhamnose, glucuronic acid, glucose, galactose, xylose, arabinose, and fucose with the sulfate groups occurring at the 3-O- and 4-O-positions. The main sugar residues of the backbone of AGP33 were found to be $1 \rightarrow 3$-linked glucose, $1 \rightarrow 4$-linked galatose, and $1 \rightarrow 6$-linked glucose. The anticoagulant activity results of AGP33, BAGP33 and AGP33-des showed that polysaccharide with higher molecular weight and sulfate content demonstrated greater anticoagulant activity.

Acknowledgments: This study was financed by The National Natural Science Foundation (No. 31301430, 31301431) and Public Science and Technology Research Funds Projects of Ocean (No. 201505029).

Author Contributions: J.Z., J.Y., B.Z. designed the experiment. J.Z., C.Z. and W.Q. performed the experiments. J.Z., J.Y. and S.L. analyzed the data. J.Z. drafted the manuscript with the help of J.Y., S.S. and D.Z. B.Z. revised the paper. All authors discussed the results and approved the final manuscript.

Conflicts of Interest: The authors declare no conflict of interest. 


\section{References}

1. Yuan, X.C.; Zhao, W.W. Bureau of fisheries, ministry of agriculture of china. In China Fishery Statistical Yearbook; China Statistics Press: Beijing, China, 2015; p. 29.

2. Yang, J.F.; Li, Y.H.; Zhao, J.; Li, P.F.; Zhu, C.; Song, Y.H.; Zhang, L.Y.; Zhu, B.W. Isolation, structural characterization, and lymphopoiesis stimulant activity of a polysaccharide from the abalone gonad. Food Sci. Biotechnol. 2015, 24, 23-30. [CrossRef]

3. Maas, N.C.; Gracher, A.H.; Sassaki, G.L.; Gorin, P.A.; Lacomini, M.; Cipriani, T.R. Sulfation pattern of citrus pectin and its carboxy-reduced derivatives: Influence on anticoagulant and antithrombotic effects. Carbohydr. Polym. 2012, 9, 1081-1087. [CrossRef] [PubMed]

4. Ustyuzhanina, N.E.; Bilan, M.I.; Gerbst, A.G.; Ushakova, N.A.; Tsvetkova, E.A.; Dmitrenok, A.S.; Usov, A.I.; Nifantiev, N.E. Anticoagulant and antithrombotic activities of modified xylofucan sulfate from the brown alga Punctaria plantaginea. Carbohydr. Polym. 2016, 136, 826-833. [CrossRef] [PubMed]

5. Sudharsan, S.; Subhapradha, N.; Seedevi, P.; Shanmugam, V.; Madeswaran, P.; Shanmugam, A.; Srinivasan, A. Antioxidant and anticoagulant activity of sulfated polysaccharide from Gracilaria debilis (Forsskal). Int. J. Biol. Macromol. 2015, 81, 1031-1038. [CrossRef] [PubMed]

6. Dong, X.D.; Pan, R.J.; Deng, X.Y.; Chen, Y.T.; Zhao, G.M.; Wang, C.H. Separation, purification, anticoagulant activity and preliminary structural characterization of two sulfated polysaccharides from seacucumber Acaudina molpadioidea and Holothuria nobilis. Process Biochem. 2014, 49, 1352-1361. [CrossRef]

7. Olson, S.T.; Björk, I. Mechanism of action of heparin and heparin-like antithrombotics. Perspect. Drug Discov. Des. 1994, 1, 479-501. [CrossRef]

8. Melo, F.R.; Pereira, M.S.; Foguel, D.; Mourão, P.A. Antithrombin-mediated Anticoagulant Activity of Sulfated Polysaccharides different mechanisms for heparin and sulfated galactans. J. Biol. Chem. 2004, 279, 20824-20835. [CrossRef] [PubMed]

9. Raposo, M.F.; de Morais, R.M.; Bernardo de Morais, A.M. Bioactivity and applications of sulphated polysaccharides from marine microalgae. Mar. Drugs 2013, 11, 233-252. [CrossRef] [PubMed]

10. Raposo, M.F.; de Morais, A.M. Microalgae for the prevention of cardiovascular disease and stroke. Life Sci. 2015, 125, 32-41. [CrossRef] [PubMed]

11. Hoffman, M.; Jia, Z.; Peña, M.J.; Cash, M.; Harper, A.; Blackburn, A.R., II; Darvill, A.; York, W.S. Structural analysis of xyloglucans in the primary cell walls of plants in the subclass Asteridae. Carbohydr. Res. 2005, 340, 1826-1840. [CrossRef] [PubMed]

12. Cao, W.; Li, X.Q.; Liu, L.; Yang, T.H.; Li, C.; Fan, H.T.; Jia, M.; Lu, Z.G.; Mei, Q.B. Structure of an antitumor polysaccharide from Angelica sinensis (Oliv.) Diels. Carbohydr. Polym. 2006, 66, 149-159. [CrossRef]

13. Uzochukwu, S.; Balogh, E.; Loefler, R.T.; Ngoddy, P.O. Structural analysis by ${ }^{13} \mathrm{C}$-nuclear magnetic resonance spectroscopy of glucan extracted from natural palm wine. Food Chem. 2002, 76, 287-291. [CrossRef]

14. Seymour, F.R.; Knapp, R.D.; Bishop, S.H.; Jeanes, A. High temperature enhancement of ${ }^{13}$ C-NMR chemical-shifts of unusual dextrans, and correlation with methylation structural analysis. Carbohydr. Res. 1979, 68, 123-140. [CrossRef]

15. Cai, W.R.; Xie, L.L.; Chen, Y.; Zhang, H. Purification, characterization and anticoagulant activity of the polysaccharides from green tea. Carbohydr. Polym. 2013, 92, 1086-1090. [CrossRef] [PubMed]

16. Wijesekara, I.; Pangestuti, R.; Kim, S.K. Biological activities and potential health benefits of sulfated polysaccharides derived from marine algae. Carbohydr. Polym. 2011, 84, 14-21. [CrossRef]

17. Yang, J.H.; Du, Y.M.; Huang, R.H.; Wan, Y.Y.; Li, T. Chemical modification, characterization and structure-anticoagulant activity relationships of Chinese lacquer polysaccharides. Int. J. Biol. Macromol. 2002, 31, 55-62. [CrossRef]

18. Yang, J.H.; Du, Y.M.; Huang, R.H.; Wan, Y.Y.; Wen, Y. The structure-anticoagulant activity relationships of sulfated lacquer polysaccharide: Effect of carboxyl group and position of sulfation. Int. J. Biol. Macromol. 2005, 36, 9-15. [CrossRef] [PubMed]

19. Therho, T.T.; Hartiala, K. Method for determination of the sulfate content of glycosamino glycans. Anal. Biochem. 1971, 41, 471-476. [CrossRef]

20. Chizhov, A.O.; Dell, A.; Morris, H.R.; Haslam, S.M.; McDowell, R.A.; Shashkov, A.S.; Nifant'ev, N.E.; Khatuntseva, E.A.; Usov, A.I. A study of fucoidan from the brown seaweed Chorda filum. Carbohydr. Res. 1999, 20, 108-119. [CrossRef] 
21. Rao, P.; Pattabiraman, T.N. Reevaluation of the phenol-sulphuric acid reaction for the estimation of hexoses and pentoses. Anal. Biochem. 1989, 181, 18-22. [CrossRef]

22. Rajendra, V.; Ranbir, S.V.; Ahmad, H.W. Separation of aldononitrile acetates of neutral sugars by gas-liquid chromatography and its application to polysaccharides. J. Chromatogr. A 1973, 77, 222-227.

23. Needs, P.W.; Selvendran, R.R. Avoiding oxidative degradation during sodium hydroxide methyl iodide-mediated Carbohydrate methylation in dimethyl sulfoxide. Carbohydr. Res. 1993, 245, 1-10. [CrossRef]

24. Yang, J.F.; Zhou, D.Y.; Liang, Z.Y. A new polysaccharide from leaf of Ginkgo biloba L. Fitoterapia 2009, 80, 43-47. [CrossRef] [PubMed]

Sample Availability: Samples of the compounds are not available from the authors.

(C) 2016 by the authors; licensee MDPI, Basel, Switzerland. This article is an open access article distributed under the terms and conditions of the Creative Commons Attribution (CC-BY) license (http://creativecommons.org/licenses/by/4.0/). 